\title{
Farmers' Prosperity Through ITC Based Farmers Awareness Programme: An Evidence of Gramin Krishi Mausam Sewa
}

\author{
Shirish Sharma ${ }^{1^{*}}$, V.S. Meena ${ }^{2}$ and Amardeep Singh ${ }^{1}$
}

${ }^{1}$ Department of Agricultural Economics, College of Agriculture, S K Rajasthan Agricultural University, Bikaner, Rajasthan, India ${ }^{2} \mathrm{COA}$ Bharatpur, SKN Agricultural University, Jobner, Jaipur, Rajasthan, India

*Corresponding author: shirishswm@gmail.com (ORCID ID: 0000-0001-6032-6449)

Received: $17-03-2021$

Revised: $26-05-2021$

Accepted: 11-06-2021

\begin{abstract}
The real-time availability of weather information plays a crucial role in agricultural production, food security, and sustainable production (Haile 2005; Rathore 2013; Pandey and Singh, 2019). Thus, any slight aberration in obtaining key weather parameters by the farming community can significantly disrupt the supply chain besides jeopardizing the lives and livelihood of millions of farmers. It is well established that weather parameters influence agricultural operations farm production and productivity, while weather aberration is an important reasonor crop loss in India (Chattopadyaya et al. 2011; Rao et al. 2015; Das et al. 2018). Most of the farmers lack real-time weather-related information to make specific decisions on cropping. Further, the weather-related data for a particular crop seldom available on a single platform (Kumar et al. 2015) though the ICT is rooted firmly. It may be concluded that agriculture and its activities are mostly depend upon weather parameters. The GKMS may create an effort to help the farming community to improve its decision-making. Farmers also adopt GKMS as a tool that may help them decide regarding farming activity. This weather based agromet advisory may also help the farming community to increase the yield as well as for the reducing the cost of cultivation of crops.
\end{abstract}

\section{Highlights}

(0) The paper aims to analyze the role of Gramin Krishi Mausam Sewa for increase the income of farmers.

( GKMS improve decision-making power of farming community.

Keywords: Agricultural information, education, farm size, GKMS

Agriculture output is dependent on weather conditions. The degree of achievement of agriculture production and its economics is apprized to a significant extent by weather conditions like the best necessities of the crop are best exploited to lift the crops. Also, however, effectively adverse weather conditions, which cause moisture, thermal, wind, radiation, and organic phenomenon stress impeding crop growth and development, are managed to reduce their adversity. More to the present, it also depends on management aspects of preventing the crops from the severe atmospheric condition. Ideally, technical progress in agriculture should decrease overall dependence on weather and climate. However, the link between yield and weather/ climate doesn't appear to be decreasing. The results of meteorological situations are most pronounced on -yielding kinds of crops with increased sensitivities to environmental situations, requiring majority improvement of water, air, thermal, and nutritional conditions. The biological potential of the plants manifests itself optimally in favorable conditions and is severely diminished when conditions are adverse. This results in giant fluctuations in annual crop yields whose scale increases the rise in yields

\footnotetext{
How to cite this article: Sharma, S., Meena, V.S. and Singh, A (2021). Farmers' Prosperity Through ITC Based Farmers Awareness Programme: An Evidence of Gramin Krishi Mausam Sewa. Economic Affairs, 66(2): 319-327.
}

Source of Support: None; Conflict of Interest: None 
from the growth in agricultures' yields from the growth in agricultures' yields from the growth in agricultures' yields from the growth in agricultures' yields from agriculture growth. For this cause, the preface of agro-meteorological information is rising. Exploitation information on the impact of weather and climatic factors on agricultural productivity in an educated manner can't solely reduce damage; however, it can also build it attainable to get further yield without essential financial outlays. Thus, the weather forecast based chiefly on agroadvisories assumes considerable importance for agricultural activities. For effective planning and management of agricultural practices like a choice of cultivar, sowing, need-based application of fertilizer, pesticides, efficient irrigation and harvest, weather forecasts altogether temporal ranges are desirable. Weather forecast briefly and medium ranges significantly contribute to, creating shortterm adjustments in daily agricultural operations that minimize losses resulting from adverse weather conditions and improve yield, amount, and quality of agricultural productions.

In India, the government has developed seasonal forecasts and weather service information for farmers in rural areas since 1988. The Agromet Division of India Meteorological Department (IMD, New Delhi, India, 1875) have, through the Gramin Krishi Mausam Seva (GKMS) program, generated weather forecasts and agro-met advisories, which are disseminated as SMSs through the portal "m-Kisan" for registered users (Nesheim et al.). Beneath the public-private Partnership mode, IMD, together with private service suppliers like Reuter Market light, IFFCO Kisan (IK), NOKIA-HCL, Handygo, Mahindra Samriddhi, and CAB International, spread agro-met information. This is done by utilizing channels like SMSs, voice messages, and app-based portals to farmer communities. An agro-met information service is predicated on scientific input from meteorology coupled with agricultural information; this information package is disseminated to farmers with the aim "to enable the farmers in designing of farming operations to reduce the damage of crops beneath adverse weather conditions". It may refer to weather forecasts solely, agro-met advisories, market information, or a combination. It can be distributed to farmers for free, or it may be a paid service. The agro-met services reportedly reach over 10 million Indian farmers, which have enabled enhanced yields and reduced loss due to surprising weather variability (Govt. of India, 201516). yet however, studies still show that there are constraints associated with such problems as access, understanding, and capability to respond to such information.

The responsiveness of farmers to forecasts depends very much on the socio-economic, local infrastructure, and the agricultural system in question. The present study attempts to understand the following objectives:

1. To determine the rate of adoption of Gramin Krishi Mausam Seva (GKMS).

2. To compare the profit margin for adopters and non-adopters of Gramin Karshi Mausam Seva (GKMS).

\section{HYPOTHESES}

- $\mathrm{H}_{\mathrm{o}}$ : Factors such as age, education level, farm size, family type, household size, farming experience, use of technology during production and income have no significant influence on the adoption of GKMS.

- $\mathrm{H}_{\mathrm{o}}$ : There is no significant difference in farmer's net profit between users and non-users of GKMS.

\section{Limitations of the study}

During the investigation, many difficulties were faced with the collection of information from cultivators. The farmers usually didn't maintain any farm record and provide information on the idea of their memory, which may not be very correct. They were biased in providing information about the higher aspect of the investment and lower aspect towards productivity. However, sufficient care was taken to collect the information by cross-checking with the educated neighboring farmers and different village leaders, Gram panchayat Sarpanch etc.

\section{Mythology}

Cross-sectional research design was used to capture the information at a given point in the Bikaner district. Cross-sectional research design permits an assortment of information at a single point in time. 


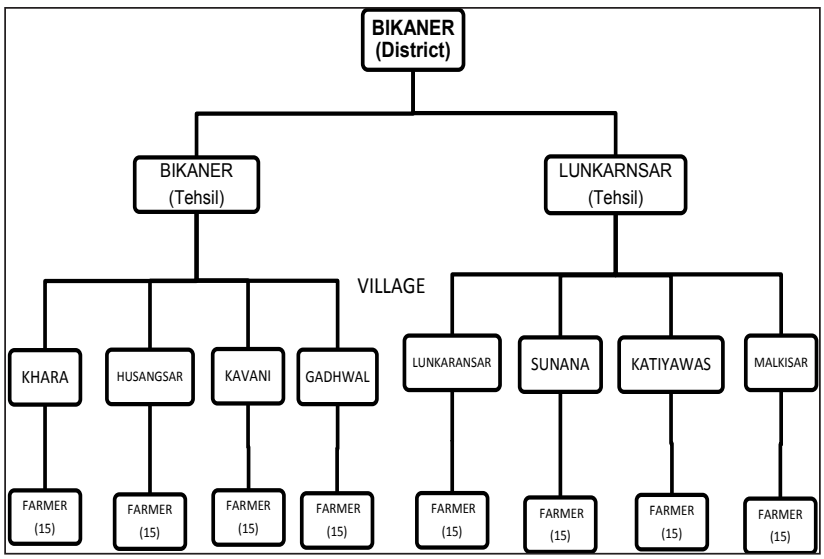

Fig. 1: Flow chart for selection of sample

Bikaner district of Rajasthan state was selected for the present study as the region is often exposed to major climate and extreme weather events. As noted by earlier studies, the region is As noted by earlier studies, the region is a semi-arid witnessing largescale weather-related agricultural risks (Singh et al. 2019). And also, the region is found to have the highest number of adopters of GKMS scheme. Further multi-stage random sampling was employed for selecting respondents. Four villages were randomly selected among the list of adopter villages registered under the GKMS. 60 beneficiary farmers were randomly selected from these villages. At the same time, the 60 respondents were randomly selected from the non-adopter villages located at a distance of $100 \mathrm{~km}$ from beneficiary village to avoid any significant biases in assessment. Thus, the sampling framework consists of 120 farmer-respondents from eight villages (60 beneficiary and 60 non-beneficiary farmers) with similar cropping patterns and geography. At the same time, the adopter farmers were considered if a farmer who adopted anyone practices/ price of information recommended by GKMS.

\section{Selection of crop}

One crop from Kharif (Groundnut) and one crop from rabi seasons (Gram) were selected. In kharif season, the groundnut crop was selected because it has a significant area under the crop. Also, it's potential for raw material supply in processing units located at Bikaner and in rabi seasons, gram was selected based on highest area under the crop production.

\section{Data collection}

Primary and secondary data were used for the present study. For primary data collection, a structured schedule was developed. For the data collection, a researcher visited in selected village. Each of the respondents was personally contacted and interviewed. Secondary data was collected through the published sources and official reports.

Analysis of data: Based on the study, the specific objective was first analyzed through descriptive analysis. A sequence of descriptive statistics was estimated using statistical methods to explore \% and frequencies of farmers who used Gramin Krishi Mausam Seva (GKMS) or didn't use Gramin Krishi Mausam Seva (GKMS). The descriptive statistical analysis describes and summarizes Gramin Krishi Mausam Seva (GKMS) use in sample farmers by age, education level, farm size, farming experience, family type, and use of advanced technology during production and income.

Profit margin: It was hypothesized that there is no significant difference in the profit margin of users and non-users of Gramin Krishi Mausam Seva (GKMS). This hypothesis was tested through net profit and compared the net profit composed between users and non-users in the second specific objective. It assumes that the fixed costs are small, which hardly affecting the sustainability of an enterprise. Such fixed costs are a cost of acquiring land, cost of acquiring farming equipment such as hand hoe, knife and stick, and cost of obtaining communication devices like mobile phone, radio, and television that do not affect enterprises' sustainability.

Net Profit $=$ Total revenue - Total variable cost

t-test was used to compare the profit margin of (GKMS) adopters and non-adopters for information providing by GKMS.

$$
t=\frac{\left|M_{x}-M_{y}\right|}{\sqrt{\frac{S_{x}^{2}}{n_{x}}+\frac{S_{y}^{2}}{n_{y}}}}
$$

where,

$M_{\mathrm{X}}=$ Mean of adopters,

$M_{y}=$ Mean of non- adopters,

$S_{x}{ }^{2}=$ Standard deviation of adopters, 
$\underset{\text { AESSRA }}{\mathbb{U}}$ Sharma et al.

$S_{y}{ }^{2}=$ Standard deviation of non-adopters,

$>55$

26

21.66

$n_{x}=$ Total number of adopters,

$n_{y}=$ Total number of non-adopters

$$
S^{2}=\frac{\Sigma(x-M)^{2}}{n-1}
$$

Where,

$S^{2}=$ Standard deviation

$x=$ individual values,

$M=$ mean,

$n=$ total number of farmers (adopter or nonadopters)

\section{RESULTS AND DISCUSSION}

\section{Social economic characteristics of farmers}

Socio-economic status is commonly conceptualized as the social standing or class of an individual or group. It is often defined as a measure of one's combined economic and social status. We focus on age, education level, farm size, farming experience, family type, use of advanced technology during production, and income. Table 1 shows that 23.33 percent farmers were educated up to secondary level, 18.34 percent completed primary education, 15.83 percent were educated up to senior secondary, and 12.50 percent farmers were graduates. This shows that more farmers were literate compared to illiterate farmers (30\%). Results show that most of the farmers were from 30-55 years of age group, contributing 65.84 percent of total respondents, followed by farmers above 55 years of age group 21.66 percent of total respondents, and only 12.50 percent farmers were of less than 30 years of age.

Table 1: Socio-economic characteristics of sample farmers in Bikaner district of Rajasthan $(\mathrm{N}=120)$

\begin{tabular}{lll}
\hline Variable & Frequency & \% \\
\hline Education & & \\
\hline Illiterate & 36 & 30.00 \\
Primary & 22 & 18.34 \\
Secondary & 28 & 23.33 \\
Senior Secondary & 19 & 15.83 \\
Graduate & 15 & 12.50 \\
\hline Age & & \\
\hline$<30$ & 15 & 12.50 \\
$30-55$ & 79 & 65.84
\end{tabular}

\begin{tabular}{lll} 
Family type & & \\
Joint & 84 & 70.00 \\
Nuclear & 36 & 30.00 \\
\hline
\end{tabular}

\begin{tabular}{lll}
\hline Farm size & & \\
\hline $\begin{array}{l}\text { Marginal and Small (0-2 } \\
\text { hectare) }\end{array}$ & 2 & 1.66 \\
Medium (>2-4 hectare) & 14 & 11.67 \\
Large (>4 hectare) & 104 & 86.67 \\
\hline Income & & 21.66 \\
\hline$<4$ Lakh & 26 & 55.84 \\
$4-7$ Lakh & 67 & 22.50 \\
>7 Lakh & 27 & 19.16 \\
\hline Farming experience & & 63.34 \\
\hline Less than 10 Year & 23 & 17.50 \\
10-34 year & 76 & \\
$>34$ year & 21 & 15.00 \\
\hline Use of technology & & 0.00 \\
\hline Advanced & 18 & 85.00 \\
Local & 0 & 102 \\
Both
\end{tabular}

Categories of age, income and farming experience were classified based on $S D \pm$ Mean.

Most of the farmers (86.67\%) fall in the large (more than 4 hectares) category, and 11.67 percent were medium farmers. Only 1.66 percent farmers were found in the small landholding category. Results indicate that most were from joint family $(70 \%)$, followed by nuclear family 30 percent. Most of the farmers were from 4-7 lakh income group 55.84 percent of total respondents, followed by farmers from less than 4 laith 21.66 percent of total respondents 21.66 per cent of total respondents above 7 lakh have 22.50 percent. Table show shows that of farmers had 10-34 years of farming experience, followed by 19.16 percent farmers less than 10 and more than 34 years of experience of 17.50 percent farmers. Table shows that 15 percent of the farmers used advanced technology while 85 percent of total respondents used both technologies.

\section{Rate of adoption of GKMS}

The first objective of analyzing rate of adoption of GKMS to farmers in selected areas, descriptive statistics were employed, which is used to describe and summarizes the use of GKMS through \% and frequencies of farmers who adopt and didn't adopt GKMS. 


\section{Frequency distribution of level of awareness}

Table 2 presents the frequency distribution of the level of awareness of sample farmers of GKMS. Maximum farmers were aware of regular information about rainfall (86.67\%) followed by regular information about sowing time $(78.33 \%)$, insect -pest attack (78.33\%), wind speed $(76.67 \%)$, temperature $(73.33 \%)$, and disease attack $(70 \%)$. Farmers were least aware of regular information about relative humidity $(60 \%)$. More than ten percent farmers were unaware of the information supplied by GKMS about wind direction, relative humidity, temperature, and insect-pest attack. It is clear that most of the farmers aware of GKMS.

Table 2: Frequency distribution of level of awareness of sample farmers of GKMS

\begin{tabular}{llll}
\hline Statements & Regularly & Sometimes & Never \\
\hline Wind direction & $37(61.67)$ & $16(26.67)$ & $7(11.67)$ \\
Wind speed & $46(76.67)$ & $9(15.00)$ & $5(8.33)$ \\
Relative humidity & $36(60.00)$ & $15(25.00)$ & $9(15.00)$ \\
Rainfall & $52(86.67)$ & $3(5.00)$ & $5(8.33)$ \\
Temperature & $44(73.33)$ & $8(13.33)$ & $8(13.33)$ \\
Sowing time & $47(78.33)$ & $7(11.67)$ & $6(10.00)$ \\
Insect-pest attack & $47(78.33)$ & $8(13.33)$ & $5(8.33)$ \\
Disease attack & $42(70.00)$ & $13(21.67)$ & $5(8.33)$ \\
\hline
\end{tabular}

Figures in parentheses show percent of total user farmers $(n=60)$.

\section{Frequency distribution of level of adoption}

Table 3 presents the frequency distribution of the level of adoption of farmers about GKMS. To check awareness, eight questions were asked in sequence. About 40 percent farmers were sowing as per recommended seed rate, while 18 percent didn't. Only 39 percent of farmers interviewed were using recommended fertilizer dose, and 37 percent were using pesticides and herbicides as per recommendations.

Table 3: Frequency distribution of level of adoption of farmers about GKMS

\begin{tabular}{lcc}
\hline Statements & Yes & No \\
\hline Do you apply seed rate according to & 42 & 18 \\
recommendation? & $(70)$ & $(30)$ \\
Do you apply fertilizer according to & 39 & 21 \\
recommendation? & $(65)$ & $(35)$ \\
Do you apply pesticides and herbicides & 37 & 23 \\
according to recommendation? & $(61.66)$ & $(38.34)$
\end{tabular}

If you know about storm than you don't give pesticides and herbicides?

If you know that rain will come than you don't sowing crops?

If you know that rain will come than you don't give irrigation?

If you know that rain will come than you give pesticides and herbicides? (Negative question)

If you know that rain will come than you harvest crop? (Negative question)

$46 \quad 14$

(76.66) (23.34)

$53 \quad 7$

(88.34) (11.66)

519

(85) (15)

$7 \quad 53$

(11.66) (88.34)

$8 \quad 52$

(13.34) (86.66)

Figures in parentheses show percent of total user farmers $(n=60)$; * A farmer with more than four positive responses was considered as adopter by a researcher and others as non-adopters.

When asked about rainfall forecast, 88.34 percent of farmers wait for sowing on pre rainfall forecast, 85 percent do not give irrigation when there is a forecast for rainfall, 88.34 percent do not give pesticides and herbicides, and 86.66 percent farmers do not harvest crops.

\section{Rate of adoption of sample farmers}

Table 4 presents the result related to rate of adoption of GKMS. Mostly middle age group farmers (30-55 year) adopted GKMS more $(65.00 \%)$ than other age groups because middle age group farmers are capable of learning and have a higher ability to accept development changes, unlike older farmers who are less likely to embrace changes. Farmers who at least completed secondary education (23.33\%) seem to adopt more of GKMS compared to illiterate farmers $(15.00 \%)$. Farmers with education have the ability to adopt easy due to their understanding and use GKMS to help them decide on production.

Large category farmers (more than 4 hectare) tend to adopt GKMS (81.67\%) as presented in the table. Large category farmers adopt more of GKMS due to their need to extend their production level through agronomy advice, community, and weather forecast. Farms who are joint family adopt more adopt GKMS (63.33\%) compared to others, as a result of when it's simple to make decisions on adoption of technology compared to nuclear family. Results show that most of the farmers used advanced and local technology with 75 percentper cent, followed by farmers using advanced technology with 67 percent. Medium (63.33\%) and low (21.67\%) farmer experienced tend to more adopt GKMS compared 
to high farmers experienced as presented in table medium and less experienced farmers adopt more GKMS as a result of they need to extend their production level though science advice, community and weather forecast.

Table 4: Rate of adoption of sample farmers in Bikaner district of Rajasthan

\begin{tabular}{|c|c|c|c|c|}
\hline \multirow{2}{*}{ Variable } & \multicolumn{2}{|c|}{ Adopter } & \multicolumn{2}{|c|}{ Non-Adopter } \\
\hline & Frequency & $\%$ & Frequency & $\%$ \\
\hline \multicolumn{5}{|l|}{ Education } \\
\hline Illiterate & 9 & 15.00 & 5 & 8.33 \\
\hline Primary & 14 & 23.33 & 0 & 0.00 \\
\hline Secondary & 14 & 23.33 & 1 & 1.67 \\
\hline $\begin{array}{l}\text { Senior } \\
\text { Secondary }\end{array}$ & 8 & 13.33 & 0 & 0.00 \\
\hline Graduate & 9 & 15.00 & 0 & 0.00 \\
\hline \multicolumn{5}{|l|}{ Age } \\
\hline$<30$ & 9 & 15.00 & 0 & 0.00 \\
\hline $30-55$ & 39 & 65.00 & 3 & 5.00 \\
\hline$>55$ & 7 & 11.67 & 3 & 5.00 \\
\hline \multicolumn{5}{|l|}{ Family Type } \\
\hline Joint & 38 & 63.33 & 2 & 3.33 \\
\hline Nuclear & 17 & 28.33 & 4 & 6.67 \\
\hline \multicolumn{5}{|l|}{ Farm size } \\
\hline $\begin{array}{l}\text { Marginal and } \\
\text { Small (1-2 } \\
\text { hectare) }\end{array}$ & 1 & 1.67 & 0 & 0.00 \\
\hline $\begin{array}{l}\text { Medium (>2-4 } \\
\text { hectare) }\end{array}$ & 5 & 8.33 & 0 & 0.00 \\
\hline $\begin{array}{l}\text { Large (>4 } \\
\text { hectare) }\end{array}$ & 49 & 81.67 & 6 & 10.00 \\
\hline \multicolumn{5}{|l|}{ Income } \\
\hline$<4$ Lakh & 21 & 35.00 & 1 & 1.67 \\
\hline 4-7 Lakh & 25 & 41.67 & 4 & 6.67 \\
\hline >7 Lakh & 9 & 15.00 & 1 & 1.67 \\
\hline
\end{tabular}

Farming experience

\begin{tabular}{lllll}
\hline Up to 10 Year & 13 & 21.67 & 0 & 0.00 \\
$10-34$ & 38 & 63.33 & 4 & 6.67 \\
$>34$ & 4 & 6.67 & 2 & 3.33 \\
\hline
\end{tabular}

Use of technology

\begin{tabular}{lllll}
\hline Advanced & 10 & 16.67 & 2 & 3.33 \\
Local & 0 & 0.00 & 0 & 0.00 \\
Both & 45 & 75.00 & 4 & 6.67 \\
\hline
\end{tabular}

Categories of age, income and farming experience were classified based on $S D \pm$ Mean .
Medium income (4-7 Lakh) and low income (less than 4 Lakh) farmers tend to adopt more GKMS $(41.67 \%$ and $35 \%)$ compared to high income farmers as presented in table 4 . Low and medium income farmers adopt more GKMS as a result of they need to extend their income level though agronomy advice, community and weather forecast with best management.

\section{Profit margin for GKMS users and non-users farmers}

Second objective of comparison of net profit of adopters and non-adopters. Profit margin analysis was done to compare net profit and to test the hypothesis that users and non-users have the same profit margin among farmers. It assumes that the fixed costs are small, which hardly affect sustainability of the enterprise. Such fixed costs are the cost of acquiring land, cost of acquiring farming equipment such as hand hoe, knife and stick that do not affect sustainability of enterprises. And t- test was used to check if it is a significant different in profit margin per hectare for getting agricultural information. These were done among farmers who use of GKMS and those who didn't use of GKMS to acquire information. In the group of user farmers, those farmers were not adopting GKMS, categorised in non-user farmers.

Profit margin analysis in Groundnut shows that the total cost per hectare for users was ₹ 54012.78 per hectare, and total revenue ₹ 165424.80 per hectare, with a net profit of ₹ 111412.01. On the other hand, the total cost per hectare for non-users was ₹ 62415.77 per hectare, and total revenue ₹ 155354.50 per hectare, with a net profit of ₹ 92938.75 per hectare (Table 5).

In Gram, the total cost per hectare for users was ₹ 32468.52 per hectare, and total revenue ₹ 70482.41 per hectare, with a net profit of ₹ 38013.89. On the other hand, the total cost per hectare for non-users was ₹ 35971.86 per hectare, and total revenue ₹ 66962.93 per hectare, with a net profit of ₹ 30991.07 per hectare (table 5). This shows that the net profit of farmers who use GKMS to access agriculture information is on top of farmers who don't use GKMS to access agriculture information.

Cost and revenue analysis show that farmers who use GKMS happens to least cost of production 
Table 5: Cost and return of sample farmers in Bikaner district of Rajasthan (₹/ha)

\begin{tabular}{lllll}
\hline \multirow{2}{*}{ Variables } & \multicolumn{3}{c}{ Groundnut } & \multicolumn{2}{c}{ Gram } \\
\cline { 2 - 5 } & Users & Non - users & Users & Non-users \\
\hline (A) Variable costs Cost of Production & & & & \\
\hline Field Preparation & 7107.41 & 7163.64 & 5838.89 & 5945.45 \\
Manure and fertilizer & 4120.37 & 5269.70 & 3174.82 & 3754.54 \\
Seed & 10770.37 & 12950.30 & 2806.30 & 3075.75 \\
Sowing & 1407.41 & 1406.06 & 1396.29 & 1412.12 \\
Weeding & 5311.11 & 5872.73 & 3529.63 & 4006.06 \\
Plant Protection & 6214.82 & 7727.27 & 3803.70 & 4775.75 \\
Irrigation & 4386.67 & 6688.79 & 2639.25 & 3520 \\
Harvesting & 9422.22 & 9303.03 & 5133.33 & 5054.54 \\
Threshing winnowing & 3888.89 & 3781.82 & 3507.40 & 3393.93 \\
Total Cost of Production & 52629.26 & 60163.34 & 31829.63 & 34938.19 \\
Transportation & 1383.519 & 2252.43 & 638.88 & 1033.67 \\
Total cost & 54012.78 & 62415.77 & 32468.52 & 35971.86 \\
\hline (B) Total revenue & & & & \\
\hline Average Yields (quantal/hectare) & 33.75 & 31.70 & 15.59 & 14.81 \\
Average price per quantal & 4266.67 & 4257.50 & 4196.29 & 4198.33 \\
Average Straw Yields (quantal/hectare) & 46.18 & 43.82 & 22.67 & 21.51 \\
Average price of straw per quantal & 463.89 & 465.67 & 222.78 & 220.83 \\
Total revenue & 165424.80 & 155354.50 & 70482.41 & 66962.93 \\
C: Net profit per hectare = Total revenue -Total variable cost & 111412.01 & 92938.75 & 38013.89 & 30991.07 \\
t-test & $5.69^{*}$ & & $4.08^{*}$ & \\
\hline Signicant & & & & \\
\hline
\end{tabular}

*Significant at $1 \%$.

compared to farmers who don't use GKMS because the least cost is attributed to the high yields low cost, related to the use of best production management. Since users of GKMS have high yields compared to non-users, they likely incur the least cost of production due to its translated translation that top yields lead to low operations cost of inputs because most of GKMS users use according to information of GKMS.

Based on t- test results as given in table 5, the test statistics under the assumption of equal variances not assumed were 5.69 and 4.08 having a significant level of 1 per cent for groundnut and gram. There's a significant distinction in farmer's net profit per hectares for getting agricultural information between users and non-users. Therefore, it's likely to reject the null hypothesis that users and non-users have a similar net profit.

The comparative cost of cultivation of one cropping year on the user and non-user farmers is represented in table 6 . The average total revenue came to
₹ 235907.20 per ha and ₹ 222317.40 per ha at sampled farms of user and non-user farmers respectively. Overall, the average total revenue in case of user farmers was found to be higher by 6.11 percent as compared to non-user farmers. The average total cost of cultivation came to ₹ 86481.30 per ha and ₹ 98387.63 per ha at sampled farms of user and non-user farmers respectively.

Table 6: Total profit margin of sample farmers in Bikaner district of Rajasthan (Per hectare)

\begin{tabular}{lllll}
\hline & Users & $\begin{array}{l}\text { Non- } \\
\text { users }\end{array}$ & Difference & $\begin{array}{l}\text { \% } \\
\text { change }\end{array}$ \\
\hline Total revenue & 235907.20 & 222317.40 & 13589.78 & 6.11 \\
Total cost & 86481.30 & 98387.63 & -11906.30 & -13.76 \\
Total income & 149425.90 & 123929.80 & 25496.11 & 20.57 \\
\hline
\end{tabular}

Overall, the average total cost of cultivation in case of non- user farmers were found to be higher by 13.76 percent as compared to user farmers. The total income came to ₹ 149425.90 per ha and ₹ 123929.80 per ha at sampled farms of user and non-user 
AESSRA

Sharma et al.

farmers respectively. Overall, the total incomes in case of user farmers were found to be higher by 20.57 percent as compared to non- user farmers. This could be due to the fact that timely advisories helped the user farmers to decide timely cultivation practices like, irrigation, weeding, spraying and harvesting etc. These timely practices reduced the labour wages, irrigation cost, pesticides costs and also lead to achieve high yield by the farmers.

\section{CONCLUSION}

Based on the analysis, farmers in Bikaner and Lunkaransar tehsil GKMS contributed to accessing agricultural information based on the information required by farmers. Most middle age group farmers (30-55 years), adopted GKMS more (65\%) compared to other age groups. The possible reason for this is that middle age group farmers are capable of learning and have a higher ability to accept development changes. Farmers who at least completed secondary education $(23.33 \%)$ seem to adopt more uses of GKMS as compared to illiterate farmers (15\%). Farmers with education have the ability to adopt easily due to their understanding and use GKMS to help them make a decision on production. Farms who belong to a joint family, used both advanced and local technology (75\%). Medium (63.33\%) and low (21.67\%) experienced farmer tend to adopt more the use of GKMS compared to other farmers. Low- and mediumincome farmers adopt more GKMS due to their need to extend their income level through agronomy advice and weather forecast information with best management.

Also, there were significant variations in farmer's net profit between users and non- users, with mean distinction of groundnut and gram respectively about ₹ 18473.26 and ₹ 7022.82 per hector, that's collaborate to reject null hypothesis "there is no significant distinction in farmer's net profit between users and non- users of GKMS". The average total revenue in case of user farmers were found to be higher by 6.11 percent as compared to non- user farmers. The average total cost of cultivation in case of non- user farmers were found to be higher by 13.76 percent as compared to user farmers. Overall, the total income in case of user farmers were found to be higher by 20.57 percent as compared to nonuser farmers.
It may be concluded that agriculture and its activities are mostly depends upon weather parameters. The GKMS may create an effort to help the farming community to improve their decision making. Farmers also adopt GKMS as a tool which may help them to take decision regarding the farming activity. This weather based agromet advisory may also help the farming community to increase the yield as well as for the reducing the cost of cultivation of crops.

\section{REFERENCES}

Agwu, A. E., Uche-Mba, U. C., and Akinnagbe, O. M. 2008. Use of information communication technologies (ICTs) among researchers, extension workers and farmers in Abia and Enugu states: Implications for a national agricultural extension policy on ICTs. J. Agric. Ext., 12(1).

Armstrong, L. and Gandhi, N. 2012. Factors influencing the use of information and communication technology (ICT) tools by the rural farmers in Ratnagiri district of Maharashtra, India. Proceedings of Third National Conference on AgroInformatics and Precision Agriculture, pp. 58-63.

Bansal, H., Sharma, S., Kumar, R. and Singh, A. 2020. The Factors Influencing and Various Technological and Socio-Economic Constraints for Crop Diversification in Haryana. Eco. Affairs, 65(3): 409-413.

Dakhore, K.K., Patel, H.R., Pandey, V. and Shekh, A.M. 2008. Economic impact assessment using agro-advisory services in middle Gujarat agro climatic zone. J. Agrometeorol., 2: 541-544.

Das, H.K., Pradhan, Dash, S.R., Rai, A.K., Behera, B.R. and Behera, N. 2019. Assessment of economic profitability of weather based agro advisory services on rice. Int. J. Agric. Sci., 11(6): 8121-8123.

Frempong, F.A. kwarteng, J., Agunga, R. and Zinnah, M.M. 2006. Challenges of infusing information and communication technologies in extension for agricultural and rural development in Ghana. J. Ext. Syst., 22: 69-82.

Govt. of India, Ministry of Agriculture and Farmers Welfare (2017b) Pocket Book of Agricultural statistics 2016-17, 39.

Ingrid, N., Line, B. and Neha, B. 2017. "What Is the Role of Agro-Met Information Services in Farmer DecisionMaking? Uptake and Decision-Making Context among Farmers within Three Case Study Villages in Maharashtra, India" Agriculture, 7: 2-16.

Jagadeesha, N., Ravindrababu, B.T., Pankaja, H.K. and Rajegowda, M.B. 2010 Adoption of agromet advisory services (AAS) for improving livelihood of rural farmers. Int. J. Agric. Sci., 6(2): 584-586.

Lata, A.M., Sreenivas, G., Lakshmi, K.V. and Reddy, D.R. 2010. Weather based agro advisories for managing the climate related crop production risks in southern Telangana region of Andhra Pradesh. Workshop Proceedings: Impact of Climate Change on Agriculture, 38: 203-206. 
Mittal, S. and Mehar, M. 2016. Socio-economic factors affecting adoption of modern information and communication technology by farmers in India: Analysis using multivariate probit model. J. Agric. Educ. Ext., 22(2): 199-212.

Mittal, S. and Kumar, P. 2000. Literacy, technology adoption, factor demand and productivity: An econometric analysis. Indian J. Agric. Econ., 55(3): 490-499.

Naik, S., Patilkhede, B., Wadekar, R. and Kumar, S. 2016. An Analysis of the Personal and Socio-economic Characteristics of the Beneficiaries of Agro-Advisory Service under Konkan Region. Adv. Life Sci., 5(7): 2679-2682.

Parida, S. 2010. Utilization of information and communication technology (ICT) tools by staff and students in universities. Ph.D. Thesis, University of Agricultural Sciences, Dharwad.

Patidar, R. 2015. A study on role of online communication in transfer of agricultural technology. Ph.D. Thesis, Jawaharlal Nehru Krishi Vishwa Vidyalaya, Jabalpur.

Rana, R.S., Prasad, R. and Kumar, S. 2005 Reliability of medium range weather forecast in mid hill region of Himachal Pradesh. J. Agrometeorol., 7(2): 297.

Rao, G.P. and Manikandan, N. 2008. Economic impact of agrometeorological advisory services over the central zone of Kerala. J. Agrometeorol., 10: 230-234.

Rathore, L.S. and Maini, P. 2008. Economic impact assessment of agro-meteorological advisory service of National centre for medium range weather forecasting, Report no. NMRF/ PR/01/2008,104.
Riyajuddin. 2005. Role of online communication in technology dissemination. Ph.D. Thesis, Chandra Shekhar Azad University of Agriculture and Technology, Kanpur.

Saxena, R., Gupta, K.C. and Mathur, P. 2015. Economic impact analysis of weather based agromet advisories on crops under climate change scenario. J. Progress. Agric., 6(1): 100-102.

Singh Naveen, P., Srivastava, S.K., Sharma, S., Anand, B., Singh, S. and Ranjith, P.C. 2020. Dynamics of socioeconomic factors affecting climate vulnerability and technology adoption: Evidence from Jodhpur district of Rajasthan. Indian J. Tradit. Know., 19(1): 192-196.

Uaiene, R.N., Arndt, C. and Masters, W.A. 2009. Determinants of agricultural technology adoption in Mozambique. Ministry of planning and development, Republic of Mozambique, Tete, pp. 18-26.

Vashisth, A., Singh, R., Das, D.K. and Baloda, R. 2013. Weather based agromet advisories for enhancing the production and income of the farmers under changing climate scenario. Int. J. Agric. Food Sci. Technol., 4(9): 847-850.

Verma, P.K., Chaudhary, J.L. and Chandrakar, M.R. 2015. Comparative economic assessment of kharif Paddy with and without Agro-Advisory Services under AICRPAMNICRA at Mahasamund district of Chhattisgarh. Mausam., 66(2): 201-204. 
